\title{
Clinical and laboratory parameters by age for patients diagnosed with multiple sclerosis between 2000 and 2015
}

\author{
Inga Małecka ${ }^{1}$, Joanna Przybek-Skrzypecka ${ }^{2}$, Katarzyna Kurowska ${ }^{1}$, Dagmara Mirowska-Guzel ${ }^{3}$, \\ Anna Członkowska ${ }^{1}$ \\ ${ }^{1} 2^{\text {nd }}$ Department of Neurology, Institute of Psychiatry and Neurology, Warsaw, Poland \\ ${ }^{2}$ Department of Ophthalmology, Medical University of Warsaw, Poland \\ ${ }^{3}$ Centre for Preclinical Research and Technology (CePT), Department of Experimental and Clinical Pharmacology, \\ Medical University of Warsaw, Poland
}

\begin{abstract}
Aim of the study. To compare the demographic, clinical and laboratory characteristics of patients with multiple sclerosis (MS) analysed based on the age at which they were diagnosed.

Clinical rationale for the study. Most cases of MS are diagnosed between the ages of 20 and 40 years, but the clinical characteristics of patients with MS over this age range have rarely been studied.

Material and methods. 182 patients diagnosed with MS between 2000 and 2015 were divided into four groups by age at diagnosis: $<30$ years $(n=62), 30-39$ years $(n=54), 40-49$ years $(n=27)$, and $\geq 50$ years $(n=39)$. The demographic, clinical and laboratory features of each age group were investigated and between-groups comparisons analysed.

Results. There were no significant differences in the female-to-male ratio between groups, which was close to 3:1 in every group $(p=0.98)$. Motor symptoms were more common as the first manifestation of MS with increasing age $(<30: 19.3 \% ; 30-39: 37.0 \%$; 40-49: 44.4\%; $\geq 50: 61.5 \%)$. Visual and sensory symptoms were responsible for nearly half of first manifestations in patients $<30$ to 49 , but affected a significantly lower proportion of patients in the oldest group $(p=0.01)$. Median (interquartile range [IQR]) Expanded Disability Status Scale at diagnosis was higher with advancing age (2 [1.5-3], 2.25 [1.5-3.5], 3 [2-3.5], and 3.5 $[3-5] ; \mathrm{p}<0.01)$. There was also a higher proportion of patients with progressive forms of the disease with age, especially primary progressive MS $(0.0 \%, 3.7 \%, 14.8 \%$, and $51.3 \% ; p<0.01)$. The median (IQR) time needed to confirm the diagnosis of MS became significantly longer as age increased (7 [2-25], 9 [2-32], 12 [6-58], and 26 [12-60] months; $p<0.01)$. In laboratory tests, significant differences were found only in the rate of post-contrast enhancement by magnetic resonance imaging, which was lower in the older age groups $(63.2 \%, 50.0 \%, 31.6 \%$, and $30.0 \% ; p<0.01)$.

Conclusions and clinical implications. Our study indicates significant differences in the demographic and clinical picture of MS depending on the age of the patient at diagnosis. Diagnostic delay in older patients is a common problem, and this study shows the features of later forms of MS to help inform neurologists and improve time to diagnosis.
\end{abstract}

Key words: Multiple sclerosis, age at diagnosis, time from first symptoms to diagnosis, clinical differences

(Neurol Neurochir Pol 2021; 55 (4): 387-393)

\section{Introduction}

Multiple sclerosis (MS) is the most common cause of neurological disability in young adults in the developed world [1]. MS can follow very different patterns of evolution and variable rates of disability accumulation. Three classifications of MS have been defined based on age at onset: childhood-onset MS ( $<18$ years), adult-onset MS (AOMS) (18-49 years) and late-onset MS (LOMS) ( $\geq 50$ years). The clinical picture of MS appears different depending on the age at diagnosis, with 
the course of the disease tending to be more progressive and disabling in LOMS [2]. Most cases of MS ( 70\%) are typically diagnosed between 20 and 40 years of age $[3,4]$ and yet the clinical characteristics of patients with MS over this age have rarely been studied.

\section{Clinical rationale for study}

In this retrospective study, we compared the clinical characteristics and laboratory tests results of patients with MS diagnosed at different ages at our centre from 2000 to 2015. The purpose was to investigate differences between age groups, since better understanding of the disease course and predictors of progression would be valuable. We also sought to determine whether older age at diagnosis affects the time to reach a diagnosis of MS, since knowledge of the factors affecting diagnosis delay are important to ensure timely recognition and treatment.

\section{Materials and methods}

\section{Study group}

The study population included patients diagnosed with MS at the $2^{\text {nd }}$ Department of Neurology, Institute of Psychiatry and Neurology, Warsaw, Poland between 2000 and 2015. Every adult patient who met the contemporary MS diagnostic criteria (McDonald 2000, McDonald 2005, or McDonald 2010) and did not fulfill the exclusion criteria was included, as described previously [5]. The exclusion criteria were: incomplete medical documentation, incomplete information about the differential diagnosis in inconclusive cases, and patient documentation indicating that the MS diagnosis had already been made before attending our department. The database used for further analysis was created from the available records stored at the Institute.

\section{Data analysis}

Patients were divided into subgroups according to their age at diagnosis: $18-29$ years, $30-39,40-49$, and $\geq 50$. Then, we analysed the difference between these groups for chosen demographic and clinical features: sex distribution, first documented symptoms and signs of MS, patient report of undocumented symptoms in the time preceding a documented onset of MS, dominating neurological syndrome at time of diagnosis, disability level measured by the Expanded Disability Status Scale (EDSS), differences in time and number of in-patient stays needed to confirm the diagnosis of MS, and clinical course of the disease preceding the diagnosis. Differences were also analysed in magnetic resonance imaging (MRI) features (including the fulfillment of Barkhof and Tintore criteria and presence of post-contrast enhancement), cerebrospinal fluid (CSF) parameters (including immunoglobulin $\mathrm{G}[\mathrm{IgG}]$ index and oligoclonal bands $[\mathrm{OCB}]$ ), and the pattern of visual evoked potentials (VEP) (abnormal P100 latency).

\section{Statistical assessment}

Quantitative data are presented as median and interquartile range (IQR) values due to non-normal distribution (mean and standard deviation were shown only for reference), while qualitative data are presented as percentage frequency. Differences in the quantitative variables, EDSS score and time from the first clinical symptom to the diagnosis of MS were evaluated using the Wilcoxon test for two-group comparison and the Kruskal-Wallis test for multi-group comparison. Differences in qualitative parameters, which comprised the rest of our data, were assessed using the Chi-square test or Fisher's exact test. Values of $p<0.05$ were considered significant. Statistical analysis was performed using SAS 15.1 software.

\section{Results}

\section{General features of studied group}

Out of 193 patients diagnosed with MS in our department between 2000 and 2015, 182 were analysed; seven patients were excluded due to incomplete documentation and four due to an earlier diagnosis of MS. Of the 182 patients studied, $62(34 \%)$ were diagnosed before the age of $30,54(29.7 \%)$ were diagnosed aged 30-39, 27 (14.8\%) were diagnosed aged 40-49, and $39(21.4 \%)$ were diagnosed aged $\geq 50$.

\section{Demographic and clinical characteristics}

Differences in demographic and clinical characteristics between the age groups are shown in Table 1 . There was a predominance of women in all age groups with a female-to-male ratio of close to $3: 1$, and no significant differences between groups $(\mathrm{p}=0.98)$.

There was no difference in the percentage of patients who reported undocumented neurological symptoms before the documented onset of MS, which was $38.5-40.7 \%$ of patients in all age groups $(\mathrm{p}=0.41)$. The type of first documented symptom of MS differed between groups: motor dysfunction was far less common in patients aged $<30$ years or 30-39 compared to those aged $\geq 50$, while there was a prevalence of sensory symptoms and visual symptoms in the younger groups $(\mathrm{p}=0.01)$. A detailed neurological examination at the time of diagnosis also differed between age groups. The most significant feature of patients aged $<30$ was a predominance of sensory dysfunction and a relatively common lack of any neurological dysfunction at the time of diagnosis. In patients aged 30-39, there was still a high percentage of minimal neurological signs, but a higher proportion of motor signs at first examination than in the youngest group. In patients aged $40-49$ or $\geq 50$, motor dysfunction became a dominating feature, followed by multifocal syndrome in those $\geq 50(\mathrm{p}<0.01)$. Median (IQR) EDSS at the time of diagnosis was significantly higher with increasing age ( $<30: 2$ [1.5-3]; 30-39: 2.25 [1.5-3.5]; 40-49: $3[2-3.5] ; \geq 50: 3.5[3-5]$ ). Median (IQR) time to reach a diagnosis of MS was longer with increasing age: 7 [2-25] months in patients $<30$ ( $\mathrm{p}<0.05 v s .40-49$ and $\geq 50), 9[2-32]$ months 
Table 1. Demographic and clinical characteristics of patients by age group

\begin{tabular}{|c|c|c|c|c|c|}
\hline & $\begin{array}{c}\text { Group I } \\
(18-29 y) \\
n=62\end{array}$ & $\begin{array}{c}\text { Group II } \\
(30-39 \text { y) } \\
n=54\end{array}$ & $\begin{array}{c}\text { Group III } \\
(40-49 y) \\
n=27\end{array}$ & $\begin{array}{c}\text { Group IV } \\
\begin{array}{c}(\geq 50 \mathrm{y}) \\
n=39\end{array}\end{array}$ & P-value \\
\hline Female:male ratio & $3.4: 1$ & $3.1: 1$ & 2.8:1 & $2.9: 1$ & ${ }^{*} p=0.98$ \\
\hline \multicolumn{6}{|c|}{ First documented symptom of MS, \% } \\
\hline Motor & 19.3 & 37.0 & 44.4 & 61.5 & \multirow{5}{*}{$\begin{array}{l}{ }^{*} p=0.01 \\
{ }^{* *} p<0.05 \text { for } \mathrm{I} \\
\text { IV; II/IV }\end{array}$} \\
\hline Sensory & 22.6 & 18.5 & 22.2 & 10.2 & \\
\hline Visual & 22.6 & 25.9 & 18.5 & 5.1 & \\
\hline Brainstem & 14.5 & 9.3 & 11.1 & 7.7 & \\
\hline Cerebellar & 19.3 & 9.3 & 3.7 & 12.8 & \\
\hline \multicolumn{6}{|c|}{ Dominating neurological syndrome at diagnosis, \% } \\
\hline No/minimal signs & 14.5 & 14.8 & 7.4 & 0.0 & \multirow{7}{*}{$\begin{array}{l}{ }^{*} p<0.01 \\
{ }^{* *} p<0.05 \text { for I/II; } \\
\text { I/III; I/IV; II/III; II/IV }\end{array}$} \\
\hline Pyramidal & 8.0 & 29.6 & 44.4 & 46.1 & \\
\hline Sensory & 35.5 & 20.4 & 14.8 & 7.7 & \\
\hline Visual acuity loss & 6.5 & 7.4 & 3.7 & 5.1 & \\
\hline Cerebellar & 11.3 & 9.3 & 7.4 & 5.1 & \\
\hline Brainstem & 9.7 & 7.4 & 3.7 & 5.1 & \\
\hline Multifocal & 14.5 & 11.1 & 18.5 & 30.8 & \\
\hline \multicolumn{6}{|l|}{ EDSS at diagnosis } \\
\hline Median (IQR) & $2(1.5-3)$ & $2.5(1.5-3.5)$ & $3(2-3.5)$ & $3.5(3-5)$ & $\begin{array}{l}{ }^{*} p<0.01 \\
{ }^{* *} p<0.05 \text { for I/III; } \\
\text { I/IV; II/IV; III/IV }\end{array}$ \\
\hline \multicolumn{6}{|c|}{ Time to diagnosis from first documented symptom } \\
\hline $\begin{array}{l}\text { Median time to diagnosis } \\
(\mathrm{IQR}) \text {, months }\end{array}$ & $7(2-25)$ & $9(2-32)$ & $12(6-58)$ & $26(12-60)$ & $\begin{array}{l}{ }^{*} p<0.01 \\
{ }^{* *} p<0.05 \text { for I/III; } \\
\text { I/IV; II/IV }\end{array}$ \\
\hline $\begin{array}{l}\% \text { of patients diagnosed } \\
\text { within } 0-11 \text { months }\end{array}$ & 66.1 & 59.3 & 40.7 & 23.1 & $\begin{array}{l}{ }^{*} p<0.01 \\
{ }^{* *} p<0.05 \text { for I/III; } \\
\text { I/IV; II/IV }\end{array}$ \\
\hline \multicolumn{6}{|c|}{ Number of in-patient stays needed for diagnosis, \% } \\
\hline 1 & 38.7 & 38.9 & 44.4 & 38.5 & \multirow[t]{4}{*}{${ }^{*} p=0.38$} \\
\hline 2 & 46.8 & 46.3 & 44.4 & 41.0 & \\
\hline 3 & 11.3 & 9.3 & 3.7 & 7.7 & \\
\hline$\geq 4$ & 3.2 & 5.6 & 7.4 & 12.8 & \\
\hline \multicolumn{6}{|l|}{ Disease course, \% } \\
\hline Relapsing remitting & 96.8 & 90.7 & 74.1 & 30.8 & \multirow{3}{*}{$\begin{array}{l}{ }^{*} p<0.01 \\
{ }^{* *} p<0.05 \text { for I/III; } \\
\text { I/IV; II/IV; III/IV }\end{array}$} \\
\hline Secondary progressive & 3.2 & 5.6 & 11.1 & 17.9 & \\
\hline Primary progressive & 0.0 & 3.7 & 14.8 & 51.3 & \\
\hline
\end{tabular}

* $\mathrm{p}$-value for comparison between all groups; **two-groups comparisons (group number/group number)

EDSS - Expanded Disability Status Scale; IQR - interquartile range; MS - multiple sclerosis; SD — standard deviation

in patients aged $30-39(\mathrm{p}<0.05 v s . \geq 50), 12[6-58]$ months in patients aged $40-49(\mathrm{p}<0.05 v s . \geq 50)$ and $26[12-60]$ months) in patients aged $\geq 50$ (trend $p<0.01$ ). As a result, the percentage of patients diagnosed 1-11 months from the first symptom of MS became lower as age increased $(\mathrm{p}<0.01)$. At the same time, there was no significant correlation between age and the number of in-patient stays needed to make a diagnosis of MS, with $38.7-44.4 \%$ of patients needing one in-patient stay and another $41-46.8 \%$ of patients needing two in-patient stays $(\mathrm{p}=0.38)$.
Disease course before diagnosis was relapsing remitting in more than $90 \%$ of patients in the $<30$ and $30-39$ categories, was $74.1 \%$ in patients aged $40-49$, but was only $30.8 \%$ in patients $\geq 50$, where the primarily progressive course dominated $(\mathrm{p}<0.01)$.

\section{Laboratory findings}

A similarly high percentage of patients in all age groups fulfilled the MRI Barkhof and Tintore criteria ( $p=0.51$ ). Most patients in the younger groups were given contrast medium (79-90\%), but only around half (51\%) of patients aged 
Table 2. Comparison of laboratory test results by age group

\begin{tabular}{|c|c|c|c|c|c|}
\hline & $\begin{array}{c}\text { Group I } \\
(18-29 \text { y) } \\
n=62\end{array}$ & $\begin{array}{c}\text { Group II } \\
(30-39 y) \\
n=54\end{array}$ & $\begin{array}{c}\text { Group III } \\
(40-49 y) \\
n=27\end{array}$ & $\begin{array}{c}\text { Group IV } \\
\begin{array}{c}(\geq 50 \mathrm{y}) \\
n=39\end{array}\end{array}$ & P-value \\
\hline \multicolumn{6}{|l|}{ MRI results } \\
\hline Barkhof and Tintore criteria fulfilled, \% & 84.7 & 83.0 & 92.6 & 74.3 & ${ }^{*} p=0.51$ \\
\hline Contrast given, $\%$ & 79 & 79 & 90 & 51 & \\
\hline Post-contrast enhancement, \% & 63.2 & 50.0 & 31.6 & 30.0 & $\begin{array}{c}{ }^{*} \mathrm{p}<0.01 \\
{ }^{* *} \mathrm{p}<0.05 \text { for I/III; I/ } \\
\text { IV; II/IV }\end{array}$ \\
\hline \multicolumn{6}{|l|}{ CSF analysis } \\
\hline Elevated lgG index, \% & 66.7 & 66.7 & 84.0 & 75.7 & ${ }^{*} p=0.34$ \\
\hline Oligoclonal bands positive, $\%$ & 92.6 & 89.4 & 95.4 & 86.7 & ${ }^{*} \mathrm{p}=0.74$ \\
\hline \multicolumn{6}{|l|}{ EEG results } \\
\hline Abnormal visual evoked potentials, $\%$ & 86.7 & 76.2 & 76.2 & 81.3 & ${ }^{*} p=0.57$ \\
\hline
\end{tabular}

${ }^{*} \mathrm{p}$-value for comparison between all groups; **two-groups comparisons (group number/group number)

CSF - cerebrospinal fluid; EEG - electroencephalogram; lgG - immunoglobulin G; MRI - magnetic resonance imaging

$\geq 50$ received it. When contrast was used, the proportion of patients with post-contrast enhancement decreased with advancing age, from $63.2 \%$ in patients $<30$ to $30 \%$ in patients aged $\geq 50(p<0.01)$. In an analysis of CSF, the percentage of patients with elevated IgG index was not significantly higher with age $(\mathrm{p}=0.34)$, although the two oldest groups had numerically higher proportions than the younger age groups. Age had no influence on the proportion of patients with positive $\mathrm{OCB}$, which was high in all groups $(\mathrm{p}=0.74)$. The percentage of patients with abnormal VEPs was also not significantly different across the age groups $(\mathrm{p}=0.57)(\mathrm{Tab} .2)$.

\section{Discussion}

MS is commonly perceived as a disease of young adults, but in fact it can start at any age. It is of the utmost importance to know the differences in the clinical picture of MS depending on age at onset or diagnosis. A number of studies have compared young MS patients to those whose disease started at 50 or later $[6,8-12,13-15]$, but, to the best of our knowledge, none of them have compared patients in different age groups in relation to their age at diagnosis, or concerned a central-eastern Europe population.

Our study shows that the percentage of patients diagnosed after 50 is higher $(21.4 \%)$ than the percentage of LOMS patients in other studies (1.1-12.7\%) [6-14], but is similar to the percentage of patients $(21.3 \%)$ in an Italian study where MS started at 40 years or older [15]. In our study, the time from the first documented symptom to the diagnosis of MS increased significantly with the age of the patient, suggesting that the diagnostic process is more challenging in older patients. Similar results were obtained by Kis et al. who observed a longer mean time to diagnosis in LOMS patients (three years) compared to younger patients (one year) [9]. A Portuguese study also demonstrated diagnostic delay in older patients [16].
In our study, we found that the proportion of progressive forms of MS was higher in older patients, which may be a factor that contributes to delay in diagnosis. In other studies, delay in diagnosis was related to the primary progressive form of MS $[16,17]$, prolonged time to first medical consultation [18, 19], patients born in earlier decades [20, 21], and coexisting diseases [22, 23]. Our age groups were not distributed evenly in relation to the different $\mathrm{McD}$ onald criteria used, and this raises the question of the influence this might have on median time to diagnosis. However, as we have proven in another study [Przybek-Skrzypecka 2020], differences in time to diagnosis depending on the type of criteria used were not significant in our Department (mean time in months: McDonald $2000-$ $39.1 \pm 68.4$; McDonald 2005 - 36.2 \pm 58.5 ; McDonald 2010 $33.6 \pm 68.2$ ). Also, we did not have enough pre-hospitalisation data to examine other factors that may have contributed to the prolongation of diagnostic process, although we found that number of hospitalisations was not a factor that differed significantly between the age groups.

We noted differences in the clinical picture of MS across the age groups. We observed that motor symptoms were the first documented symptom and sign of MS in all age groups except for patients aged $<30$. The presence of motor symptoms was found to be higher as age increased. Our findings are similar to those in studies comparing patients with AOMS and LOMS, where motor deficit was found to be the most common neurological manifestation among late-onset patients, encompassing more than half of the studied group (54.8-80\%) [6, 9, 10, 12, 13, 24, 25]. Overrepresentation of motor deficit in older patients may be connected to the overrepresentation of the primary progressive form of the disease. However, Cossburn et al. found that in a population of patients with only relapsing remitting MS, there was also a higher percentage of patients with motor signs at the beginning of the disease [11]. We observed that the frequency of 
sensory symptoms and optic neuritis as a first manifestation of MS was similar up to 50 years, but then deceased, which is consistent with studies comparing AOMS and LOMS [9, 12, 14].

As mentioned, progressive forms of MS, mainly primary progressive MS, were more common in older patients. Typically, primary progressive MS starts 10 years later than relapsing remitting MS (around the age of 38-41) [26-29]. Similarly, significant differences in the percentage of primary progressive MS patients in the AOMS versus LOMS group have been described in other studies (AOMS: 5-11\%; LOMS: 20-83\%) $[6,8-10,12,13,25,30]$. There appears to be a turning point, somewhere between 40 and 50, where a rising advantage of degeneration over demyelination processes changes the clinical picture of the disease to a progressive one with dominating motor deficits.

However, in our youngest age groups there were some cases of secondary progression. Three of those patients, a female aged 22, a female aged 34, and a male aged 39 at diagnosis, had already entered the progressive phase because of the long gap between first symptom and diagnosis (36-58 months). Two other cases were a young woman aged 19 , and a 31-year-old male who had a short but aggressive history of disease with a progressive-relapsing course.

EDSS at the time of diagnosis was also influenced by age in our study. We found mean EDSS significantly higher with each passing decade. Our results are comparable to those of Kis et al. where mean EDSS in a late-onset MS group was significantly higher than an adult-onset MS group (3.5 vs. 2.7) [9] and similar to a Canadian study, where the percentage of patients with EDSS of 3.0 or more at first neurological examination was higher in LOMS (66.0\%) than in AOMS (44.7\%) [8]. Most authors agree that the older the patient is at MS onset, the more rapid the accumulation of disability [12, 14, 15, 29-39]. However, it was observed by Tremlett et al. that this was only true for patients up to EDSS 3.0 and beyond this value, which was a turning point for relapsing remitting MS becoming secondary progressive MS, time of onset of MS had no influence on speed of disability accumulation [8]. This observation has been seconded by other authors who observed that age at disease onset only affected the severity of the relapsing remitting phase, not the secondary progressive phase $[40,41]$.

Brain MRI can become less specific in older MS patients, due to concomitant diseases and different localisation of lesions, necessitating an additional spine MRI to make a diagnosis $[7,9]$. However, in our study, we found that brain MRI that fulfilled Barkhof and Tintore criteria was similarly specific in all age groups. The only parameter that became significantly less frequent in older groups was the presence of contrast enhancement. Our results are similar to those of other studies, where Barkhof and Tintore criteria fulfillment stayed high in the late-onset group (65-88\%) [7, 10, 25], while contrast enhancement decreased (AOMS: 61-63\%; LOMS: 15-35\%) [7, 9]. Interestingly, Jasek et al. showed that conventional measures such as T2-lesion load or brain atrophy measures were similar in AOMS and LOMS groups, and that only more sophisticated methods indicated more axonal damage in LOMS [42].

In our study, a high percentage of patients had OCBs in CSF, and this was observed across all age groups, consistent with other studies $[9,10,24,30]$, which indicates that OCB is an effective diagnostic tool in patients of all ages. Patients with abnormal VEP also predominated in our study, in line with the work of Kis et al. (AOMS: 70\%; LOMS: 86\%) [9] and Noseworthy et al. (AOMS: 67\%; LOMS: 62\%) [43]. Of note, other diseases of the visual system are common in older patients, so the specificity of an abnormal VEP test may decrease with age, despite its high sensitivity.

We are aware that the present study has certain limitations. Small groups, a single-centre study and retrospective design may have affected our results. However, our centre was a reference hospital and our diagnostic procedure was carefully tailored to meet current diagnostic criteria.

\section{Conclusions and clinical implications}

We found significant differences in the demographic and clinical picture of MS depending on the age of the patient at diagnosis. Patients aged $\geq 50$ had a more severe clinical picture of MS at diagnosis, with greater neurological impairment, commonly affecting the pyramidal system, and they often had a progressive course. Differences in the clinical picture began to occur between 40 and 50 or even before. A delay in diagnosis was common in older patients, despite diagnostic tools remaining reliable across all age groups.

These findings related to the different features of MS with age at onset may help to inform neurologists and improve time to diagnosis.

Ethical permission: This study was approved by the Institute of Psychiatry and Neurology Bioethics Committee.

Funding: The work was supported financially as part of the internal funding of the Institute of Psychiatry and Neurology. Conflict of interest: None.

\section{References}

1. Thompson A, Baranzini S, Geurts J, et al. Multiple sclerosis. The Lancet. 2018; 391(10130): 1622-1636, doi: 10.1016/s01406736(18)30481-1.

2. Martinelli V, Rodegher M, Moiola L, et al. Late onset multiple sclerosis: clinical characteristics, prognostic factors and differential diagnosis. Neurol Sci. 2004; 25 Suppl 4: S350-S355, doi: 10.1007/s10072004-0339-8, indexed in Pubmed: 15727232.

3. Ascherio A, Munger KL. Epidemiology of multiple sclerosis: from risk factors to prevention-an update. Semin Neurol. 2016; 36(2): 103-114, doi: 10.1055/s-0036-1579693, indexed in Pubmed: 27116717.

4. Confavreux C, Vukusic S. Natural history of multiple sclerosis: a unifying concept. Brain. 2006; 129(Pt 3): 606-616, doi: 10.1093/brain/ awl007, indexed in Pubmed: 16415308. 
5. Przybek-Skrzypecka J, Małecka I, Członkowska A, et al. Demographic and clinical profile of patients with multiple sclerosis diagnosed over the last 30 years according to different diagnostic criteria. Neurol Neurochir Pol. 2020; 54(2): 169-175, doi: 10.5603/PJNNS.a2020.0027, indexed in Pubmed: 32242912.

6. Polliack ML, Barak $\mathrm{Y}$, Achiron A. Late-onset multiple sclerosis. J Am Geriatr Soc. 2001; 49(2): 168-171, doi: 10.1046/j.15325415.2001.49038.x, indexed in Pubmed: 11207871.

7. de Seze J, Delalande S, Michelin E, et al. Late onset multiple sclerosis. Rev Neurol (Paris). 2002; 158(11): 1082-1087, indexed in Pubmed: 12451340 .

8. Tremlett $\mathrm{H}$, Devonshire V. Is late-onset multiple sclerosis associated with a worse outcome? Neurology. 2006; 67(6): 954-959, doi: 10.1212/01.wnl.0000237475.01655.9d, indexed in Pubmed: 17000960 .

9. Kis B, Rumberg B, Berlit P. Clinical characteristics of patients with late-onset multiple sclerosis. J Neurol. 2008; 255(5): 697-702, doi: 10.1007/s00415-008-0778-x, indexed in Pubmed: 18283394.

10. Arias M, Dapena D, Arias-Rivas S, et al. Late onset multiple sclerosis. Neurologia. 2011; 26(5): 291-296, doi: 10.1016/j.nrl.2010.09.008, indexed in Pubmed: 21163234.

11. Cossburn M, Ingram G, Hirst C, et al. Age at onset as a determinant of presenting phenotype and initial relapse recovery in multiple sclerosis. Mult Scler. 2012; 18(1): 45-54, doi: 10.1177/1352458511417479, indexed in Pubmed: 21865412.

12. Bove RM, Healy B, Augustine A, et al. Effect of gender on late-onset multiple sclerosis. Mult Scler. 2012; 18(10): 1472-1479, doi: 10.1177/1352458512438236, indexed in Pubmed: 22383227.

13. Roohani P, Emiru T, Carpenter A, et al. Late onset multiple sclerosis: Is it really late onset? Mult Scler Relat Disord. 2014; 3(4): 444-449, doi: 10.1016/j.msard.2014.02.004, indexed in Pubmed: 25877055.

14. Shirani A, Zhao Y, Petkau J, et al. Multiple sclerosis in older adults: the clinical profile and impact of interferon Beta treatment. Biomed Res Int. 2015; 2015: 451912, doi: 10.1155/2015/451912, indexed in Pubmed: 25922836.

15. D'Amico E, Patti F, Zanghì A, et al. Late-onset and young-onset relapsing-remitting multiple sclerosis: evidence from a retrospective longterm follow-up study. Eur J Neurol. 2018; 25(12): 1425-1431, doi: 10.1111/ene.13745, indexed in Pubmed: 29956427.

16. Aires A, Barros A, Machado C, et al. Diagnostic delay of multiple sclerosis in a Portuguese population. Acta Med Port. 2019; 32(4): 289 294, doi: 10.20344/amp.11187, indexed in Pubmed: 31067423.

17. Brola W, Sobolewski P, Żak M, et al. Profile of Polish patients with primary progressive multiple sclerosis. Mult Scler Relat Disord. 2019; 33: 33-38, doi: 10.1016/j.msard.2019.05.009, indexed in Pubmed: 31146082.

18. Fernández 0 , Fernández V, Arbizu T, et al. Novo Group. Characteristics of multiple sclerosis at onset and delay of diagnosis and treatment in Spain (the Novo Study). J Neurol. 2010; 257(9): 1500-1507, doi: 10.1007/s00415-010-5560-1, indexed in Pubmed: 20383518.

19. Adamec I, Barun B, Gabelić T, et al. Delay in the diagnosis of multiple sclerosis in Croatia. Clin Neurol Neurosurg. 2013; 115 Suppl 1: S70-S72, doi: 10.1016/j.clineuro.2013.09.025, indexed in Pubmed: 24321160.

20. Celius EG, Smestad C. Change in sex ratio, disease course and age at diagnosis in Oslo MS patients through seven decades. Acta Neurol Scand Suppl. 2009(189): 27-29, doi: 10.1111/j.16000404.2009.01208.x, indexed in Pubmed: 19566494.
21. Lavorgna L, Borriello G, Esposito S, et al. Impact of early diagnosis on clinical characteristics of an Italian sample of people with multiple sclerosis recruited online. Mult Scler Relat Disord. 2019; 27: 239-246, doi: 10.1016/j.msard.2018.10.113, indexed in Pubmed: 30419509.

22. Marrie RA, Horwitz R, Cutter G, et al. Comorbidity delays diagnosis and increases disability at diagnosis in MS. Neurology. 2009; 72(2): 117-124, doi: 10.1212/01.wnl.0000333252.78173.5f, indexed in Pubmed: 18971448.

23. Thormann A, Sørensen PS, Koch-Henriksen N, et al. Comorbidity in multiple sclerosis is associated with diagnostic delays and increased mortality. Neurology. 2017; 89(16): 1668-1675, doi: 10.1212/ WNL.0000000000004508, indexed in Pubmed: 28931645.

24. Lotti CB, Oliveira AS, Bichuetti DB, et al. Late onset multiple sclerosis: concerns in aging patients. Arq Neuropsiquiatr. 2017; 75(7): 451-456, doi: 10.1590/0004-282X20170070, indexed in Pubmed: 28746432.

25. Bermel RA, Rae-Grant AD, Fox RJ. Diagnosing multiple sclerosis at a later age: more than just progressive myelopathy. Mult Scler. 2010; 16(11): 1335-1340, doi: 10.1177/1352458510377334, indexed in Pubmed: 20670982.

26. Weinshenker BG, Bass B, Rice GP, et al. The natural history of multiple sclerosis: a geographically based study. I. Clinical course and disability. Brain. 1989; 112 ( Pt 1): 133-146, doi: 10.1093/brain/112.1.133, indexed in Pubmed: 2917275.

27. Vukusic $S$, Confavreux C. Primary and secondary progressive multiple sclerosis. J Neurol Sci. 2003; 206(2): 153-155, doi: 10.1016/s0022-510x(02)00427-6, indexed in Pubmed: 12559503.

28. Riise T, Grønning M, Fernández 0 , et al. Early prognostic factors for disability in multiple sclerosis, a European multicenter study. Acta Neurol Scand. 1992; 85(3): 212-218, doi: 10.1111/j.1600-0404.1992. tb04031.x, indexed in Pubmed: 1575007.

29. Trojano M, Avolio C, Manzari C, et al. Multivariate analysis of predictive factors of multiple sclerosis course with a validated method to assess clinical events. J Neurol Neurosurg Psychiatry. 1995; 58(3): 300-306, doi: 10.1136/jnnp.58.3.300, indexed in Pubmed: 7897410.

30. Hooge JP, Redekop WK. Multiple sclerosis with very late onset. Neurology. 1992; 42(10): 1907-1910, doi: 10.1212/wnl.42.10.1907, indexed in Pubmed: 1407571.

31. Phadke JG. Clinical aspects of multiple sclerosis in north-east Scotland with particular reference to its course and prognosis. Brain. 1990; 113 ( Pt 6): 1597-1628, doi: 10.1093/brain/113.6.1597, indexed in Pubmed: 2276037.

32. White AD, Swingler RJ, Compston DA. Features of multiple sclerosis in older patients in South Wales. Gerontology. 1990; 36(3): 159-164, doi: 10.1159/000213192, indexed in Pubmed: 2227469.

33. Bergamaschi R, Berzuini $\mathrm{C}$, Romani A, et al. Predicting secondary progression in relapsing-remitting multiple sclerosis: a Bayesian analysis. J Neurol Sci. 2001; 189(1-2): 13-21, doi: 10.1016/s0022510x(01)00572-x, indexed in Pubmed: 11535229.

34. Confavreux C, Vukusic S, Adeleine P. Early clinical predictors and progression of irreversible disability in multiple sclerosis: an amnesic process. Brain. 2003; 126(Pt 4): 770-782, doi: 10.1093/brain/ awg081, indexed in Pubmed: 12615637.

35. Amato MP, Ponziani G, Bartolozzi ML, et al. A prospective study on the natural history of multiple sclerosis: clues to the conduct and interpretation of clinical trials. J Neurol Sci. 1999; 168(2): 96-106, doi: 10.1016/s0022-510x(99)00143-4, indexed in Pubmed: 10526190. 
36. Vukusic S, Confavreux C, Confavreux C, et al. Natural history of multiple sclerosis: a unifying concept. Brain. 2006; 129(Pt 3): 606-616, doi: 10.1093/brain/awl007, indexed in Pubmed: 16415308.

37. Ramachandran S, Strange RC, Jones PW, et al. Associations between onset age and disability in multiple sclerosis patients studied using MSSS and a progression model. Mult Scler Relat Disord. 2014; 3(5): 593-599, doi: 10.1016/j.msard.2014.06.002, indexed in Pubmed: 26265271.

38. Alroughani R, Akhtar S, Ahmed S, et al. Is Time to Reach EDSS 6.0 Faster in Patients with Late-Onset versus Young-Onset Multiple Sclerosis? PLoS One. 2016; 11(11): e0165846, doi: 10.1371/journal. pone.0165846, indexed in Pubmed: 27802328.

39. Cierny D, Lehotsky J, Hanysova S, et al. The age at onset in Multiple Sclerosis is associated with patient's prognosis. Bratisl Lek Listy. 2017; 118(6): 374-377, doi: 10.4149/BLL_2017_071, indexed in Pubmed: 28664749.
40. Scalfari A, Neuhaus A, Daumer M, et al. The natural history of multiple sclerosis: a geographically based study 10: relapses and long-term disability. Brain. 2010; 133(Pt 7): 1914-1929, doi: 10.1093/brain/ awq118, indexed in Pubmed: 20534650.

41. Guillemin F, Baumann C, Epstein J, et al. LORSEP Group. Older age at multiple sclerosis onset is an independent factor of poor prognosis: A population-based cohort study. Neuroepidemiology. 2017; 48(3-4): 179-187, doi: 10.1159/000479516, indexed in Pubmed: 28793296.

42. Jasek $Ł$, Śmigielski J, Siger M. Late onset multiple sclerosis - multiparametric MRI characteristics. Neurol Neurochir Pol. 2020; 54(3): 265-271, doi: 10.5603/PJNNS.a2020.0036, indexed in Pubmed: 32368786.

43. Noseworthy J, Paty D, Wonnacott T, et al. Multiple sclerosis after age 50. Neurology. 1983; 33(12): 1537-1544, doi: 10.1212/ wnl.33.12.1537, indexed in Pubmed: 6606140. 